\title{
BMJ Open Association between organisational and workplace cultures, and patient outcomes: systematic review protocol
}

\author{
J Braithwaite, J Herkes, K Ludlow, G Lamprell, L Testa
}

To cite: Braithwaite J, Herkes J, Ludlow K, et al. Association between organisational and workplace cultures, and patient outcomes: systematic review protocol. BMJ Open 2016;6: e013758. doi:10.1136/ bmjopen-2016-013758

- Prepublication history for this paper is available online. To view these files please visit the journal online (http://dx.doi.org/10.1136/ bmjopen-2016-013758).

Received 5 August 2016 Revised 4 October 2016 Accepted 5 October 2016

CrossMark

Centre for Healthcare

Resilience and

Implementation Science, Australian Institute of Health Innovation, Macquarie University, North Ryde, New South Wales, Australia

Correspondence to Professor J Braithwaite; jeffrey.braithwaite@mq.edu.au

\section{ABSTRACT}

Introduction: Despite widespread interest in the topic, no current synthesis of research is available analysing the linkages between organisational or workplace cultures on the one hand, and patient outcomes on the other. This protocol proposes a systematic review to analyse and synthesise the literature to date on this topic. The resulting review will discuss characteristics of included studies in terms of the type of healthcare settings researched, the measurements of organisational and workplace culture, patient outcomes measured and the influence of these cultures on patient outcomes.

Methods and analysis: A systematic review will be conducted aiming to examine the associations between organisational and workplace cultures, and patient outcomes, guided by the Preferred Reporting Items for Systematic review and Meta-Analysis Protocols (PRISMA-P) statement. An English language search of abstracts will be executed using the following academic databases: CINAHL, EMBASE, Ovid MEDLINE, Web of Science and PsycINFO. The review will include relevant peer-reviewed articles from randomised controlled trials (RCTs), non-RCTs, controlled before and after studies, interrupted time series studies, cross-sectional analyses, qualitative studies and mixed-method studies. Multiple researchers will be involved in assessing the quality of articles for inclusion in the review. This protocol documents a detailed search strategy, including terms and inclusion criteria, which will form the basis of the subsequent systematic review.

Ethics and dissemination: Ethics approval is not required as no primary data will be collected. Results will be disseminated through a peer-reviewed publication and conference presentations.

\section{INTRODUCTION \\ Rationale}

A positive and productive culture, within workplaces and across the wider organisation, is believed to be an important factor in determining the quality of clinical and organisational outputs and outcomes. ${ }^{1}$ In healthcare settings, the possible downstream effects of culture are particularly important

\section{Strengths and limitations of this study}

- We lack adequate understanding of how cultural characteristics in healthcare organisations and workplaces are related to patient outcomes.

- Organisational and workplace cultures are hard to define, making inclusion criteria subjective.

- The review will include studies ranging from randomised controlled trials to mixed-method studies

- We will follow the Preferred Reporting Items for Systematic review and Meta-Analysis Protocols (PRISMA-P), Grading of Recommendations Assessment, Development and Evaluation (GRADE) framework and COCHRANE tools for assessing the risk of bias.

as they concern patient outcomes, which can range from morbidity, to acquired infections, to quality of life, to mortality. ${ }^{2}$ Despite these potential consequences, we do not know with sufficient confidence about the association between organisational and workplace cultures, and patient outcomes, in healthcare environments. Enhanced knowledge of this association is necessary in order to understand how to improve health systems. Past research highlights this knowledge gap ${ }^{14}$ and has laid the foundation for the proposed systematic review.

\section{Cultures and subcultures}

Culture has been described in many ways in the literature, ranging from simple definitions to complex models. ${ }^{4-7}$ Simply put, culture is a way of holistically understanding the summed characteristics of organisational behaviour, thinking and attitudes. ${ }^{8}{ }^{9}$ A predominant model of culture is the iceberg model, which refers to culture as a two-part phenomenon. ${ }^{10}$ Above the waterline are observable workplace behaviours and practices, while below the waterline lie the foundational group beliefs, attitudes, values and philosophies of the workplace. ${ }^{10}$ By way of 
comparison, Schein's 2004 tripartite model of culture includes visible organisational structures and underlying assumptions of culture. Schein's model also comprises a third level, equivalent to an 'at the waterline' level, which encompasses beliefs and values, as observed in rhetoric and anchored in behaviour. ${ }^{911}$

In organisational culture, behavioural patterns, beliefs and assumptions are shared throughout a setting. ${ }^{4}$ Subcultures can have many bases, including occupational, gender or racial distinctions. ${ }^{12}{ }^{13}$ Within this healthcare setting, there are also workplace-specific cultures, which are explicit examples of subcultures. ${ }^{14}$ Gallego $e t a l^{15}$ reported that cultural differences manifest between different service types. For example, in that study, community nursing and breast screening units had a more favourable safety attitudes culture compared with mental health wards. Such differentiated, localised workplace cultures can be analysed in terms of their similarities or their differences across the broader healthcare organisation. ${ }^{9} 14$

While there are always definitional challenges with complex social constructs, ${ }^{16}$ this protocol adopts a pluralist perspective; recognising that distinguishable workplace cultures are components of a wider organisational culture. ${ }^{14}$ Therefore, this review protocol considers organisational culture and workplace culture as researchable, index concepts.

\section{Past reviews}

Previous reviews have focused on the influence of organisational climate on patient outcomes, which MacDavitt et $a l^{2}$ define as "employees' perception of the organizational culture". In differentiating between organizational culture and climate, and focusing on the latter, MacDavitt $e t a l^{2}$ present a broad-based understanding of organisational climate mapped to the tip of the iceberg in Braithwaite's ${ }^{10}$ model. ${ }^{2}$ This protocol will complement and expand on MacDavitt $e t a l \mathrm{~s}^{2}$ review by encompassing articles on culture and climate.

Other reviews have been restrictive in their inclusion criteria, leading to a narrow understanding of the association between organisational and workplace cultures, and patient outcomes. Parmelli et $a l{ }^{4}{ }^{4}$ systematic review focused on the effects of culture change interventions on patient outcomes and healthcare performance. Owing to this limited focus, only two relevant studies were included in that systematic review. ${ }^{4}$ On the other hand, Willis $e t a l^{17}$ used a realist review method to examine relationships between interventions and sustained culture change. Separate review work has yielded results with limited generalisability by focusing on prespecified healthcare environmental variables, such as nursing culture $^{18-20}$ or surgical procedures. ${ }^{21}$ Other work by the 'Deepening our Understanding of Quality improvement in Europe' (DUQuE) team examined relationships between organisational-level culture and quality management systems. ${ }^{22}$ In contrast, other reviews have chosen a wider inclusion criteria, encompassing how organisational culture broadly affected healthcare performance. ${ }^{523}$ Our protocol offers a middle-ground, by mapping culture to the specific concept of patient outcomes in various healthcare settings.

\section{Patient outcomes}

Turning to our other major construct, patient outcomes, in ways analogous to the manner in which culture has been treated, past research has been restrictive in the search terms included for reviews. MacDavitt $e t a l^{2}$ identified 12 articles measuring patient outcomes, but only 3 of these incorporated more than one specific element of patient outcomes. Of the studies included in Parmelli et $a l \mathrm{~s}^{4}$ systematic review, one measured the frequency of handwashing practices and its association with the patient outcome of infection, ${ }^{24}$ and the second measured vitality, life satisfaction and orientation to life. ${ }^{25}$ Another example is Hesselink et als 2013 paper which concentrated on the measurement of patient discharge. ${ }^{1}$

This norm of only reporting a small number of specific patient outcomes-in systematic reviews and in original research-means that only a limited understanding of the association between culture and patient outcomes has been achieved. Hence, the current study aims to encompass a mix of patient outcomes to provide a holistic understanding of the association of outcomes with organisational and workplace cultures.

\section{Objectives}

In this protocol, we widen the scope of past reviews; we aim to thoroughly investigate the extent to which organisational and workplace cultures are associated with patient outcomes across a range of healthcare settings. Our objective in this paper is to articulate the design of a systematic review aiming to evaluate and synthesise relevant literature on this topic. Ultimately, the outcome of the review will be to offer nuanced information for researchers, managers, health professionals, clinicians, healthcare decision-makers, health policymakers and patient groups interested in understanding how cultures and outcomes relate. We are mindful, however, of what Mannion and Davies $^{26}$ have recently had to say about this topic: "attempting to enact culture change to improve performance is a difficult, uncertain, and risky enterprise".

\section{METHODS}

\section{Eligibility criteria}

\section{Participants}

Participating healthcare facilities may include hospitals, acute and primary healthcare facilities, health organisations and other health delivery services. These facilities may be public or private, and situated in metropolitan or rural locations.

\section{Indicators}

This study will use indicators that measure aspects of organisational and workplace cultures, and patient 
Table 1 Search strategy

\begin{tabular}{|c|c|c|}
\hline Search term keyword & Related terms/synonyms & $\begin{array}{l}\text { Alternative } \\
\text { terms }\end{array}$ \\
\hline $\begin{array}{l}\text { Organisational, } \\
\text { workplace culture }\end{array}$ & $\begin{array}{l}\text { Work culture OR organization* culture OR service culture OR corporate culture } \\
\text { OR work climate OR organization* climate OR service climate OR corporate } \\
\text { climate OR work ethos OR organization* ethos OR service ethos OR corporate } \\
\text { ethos OR work environment OR organization* environment OR service } \\
\text { environment OR corporate environment }\end{array}$ & $\begin{array}{l}\text { Organisation } \\
\text { Work place } \\
\text { Workplace } \\
\text { Work site } \\
\text { Worksite }\end{array}$ \\
\hline \multicolumn{3}{|c|}{ ( } \\
\hline Patient outcomes & $\begin{array}{l}\text { Patient outcome* OR patient satisfaction OR health outcome* OR patient } \\
\text { experience* OR mortality OR length of stay OR pain level OR cost of care OR } \\
\text { functional abilit* OR patient knowledge OR quality of life OR impairment }{ }^{\star} \text { OR } \\
\text { disabilit* OR readmission rate* OR adverse event* OR medication error* OR } \\
\text { patient fall* OR infection* OR decubitus ulcer }\end{array}$ & \\
\hline \multicolumn{3}{|c|}{ Pla } \\
\hline Healthcare & $\begin{array}{l}\text { Health organization* OR hospital }{ }^{\star} \text { OR health facilit* OR acute care OR primary } \\
\text { care OR health }\end{array}$ & $\begin{array}{l}\text { Organisation } \\
\text { Healthcare } \\
\text { Health care } \\
\text { Health-care }\end{array}$ \\
\hline
\end{tabular}

outcomes. Approaches to measure and assess culture and outcomes vary widely, and therefore, it is expected that the mechanisms and tools used will be heterogeneous throughout the studies reviewed.

\section{Comparisons between culture and patient outcomes}

Comparisons may be made where feasible between cultures in similar types of health setting; for example, between acute hospitals that have comparable size, economic funding and patient-nurse ratios. Cultural comparisons are also envisaged between different types of health settings such as between metropolitan and rural environments.

\section{Outcome measures}

Patient outcome measures, as detailed in the search strategy (table 1), will include objective and quantifiable measurements. The inclusion of broad terms such as 'patient outcomes' and more specific terms such as 'patient falls' recognises that studies may focus on identifiable aspects of patient outcomes.

\section{Report characteristics}

Publications will be assessed against the following inclusion criteria: English language, peer-reviewed, primary empirical research articles, published in scholarly journals. Full texts must also be available. A date restriction will not be applied to the search. Studies will include randomised controlled trials (RCTs), non-RCTs, controlled before and after (CBA) studies, interrupted time series (ITS) studies, cross-sectional analysis, qualitative studies and mixed-method studies. We believe that these methods-provided that they include valid, rigorous, peer-reviewed research on patient outcomes-can provide useful information regarding the association between organisational and workplace cultures, and patient outcomes. Grey literature will be excluded from this study as invariably such work falls outside our 'valid, rigorous, peer-reviewed' criteria.

\section{Information sources}

The search terms (table 1) will be entered into the following academic databases: CINAHL, EMBASE, Ovid MEDLINE, Web of Science and PsycINFO. Multiple search terms will be used to identify workplace and organisation cultures, patient outcomes and healthcare settings.

\section{Study records}

Data management

The initial search will be carried out by a two primary researchers (KL and $\mathrm{JH})$ using the strategy indicated in table 1 and guided by the Preferred Reporting Items for Systematic review and Meta-Analysis Protocols (PRISMA-P) statement. KL and JH will also search the reference lists of identified reviews for other relevant articles, and experts in the field will be contacted for advice on potentially appropriate articles. Other researchers in the team will sample-test the strategy for fidelity. KL will import the data into an EndNote library and will delete duplicate entries. These will be checked for accuracy by a third researcher (LT).

\section{Selection and data collection processes}

The reviewers, JH, KL, GL and LT, will compare $5 \%$ of the EndNote library to ensure a consensus across article retention. Inter-rater agreement analysis will be conducted from these results. Any inconsistencies will be discussed and resolved by the research team in the light of the research question and inclusion criteria; JB will be the final arbitrator. These four researchers will then each independently review $25 \%$ of the remaining 
abstracts in line with the inclusion criteria, followed by a full-text review of included abstracts. Reasons for excluding studies will be recorded. Information extracted from included articles will comprise the healthcare context, aspects of culture measured, methodology, sample size, intervention (if applicable) and all reported patient outcomes.

\section{Data items and definitions}

This protocol is based on ambiguous concepts, with inconsistent expert consensus on their definitions. As such, we define the variables used in this systematic review protocol (box 1).

This systematic review protocol is founded on transparent assumptions. First, as MacDavitt et $a l^{2}$ highlight, organisational culture and organisational climate are terms often used interchangeably in published literature, as the distinction between the terms is not clearcut. $^{9}{ }^{27}$ It can be argued that organisational climate is a subset of organisational culture, characterised by specific data collection tools and resources. ${ }^{5}$ Organisational culture encompasses these data collection methods in addition to other techniques. We adopted this logic to establish a view that we would include the terms 'climate', 'culture' and 'environment' in the systematic review.

\section{Outcomes and prioritisation}

Prioritisation of the search strategy items will ultimately improve the way articles are presented in the review. Priority will be given to articles which include multiple patient outcomes and measures of culture. Prioritisation will also be given to articles that study organisational or workplace culture as a whole.

\section{Risk of bias in individual studies}

The review findings will be limited by the results of the search strategy and the potential inclusion of nonrandomised studies. To assess the inherent risk of bias in individual studies, two researchers ( $\mathrm{JH}$ and LT) will actively consult the Cochrane Handbook for Systematic Reviews, specifically the Cochrane Collaboration tool for assessing the risk of bias. JH and LT will independently

\section{Box 1 Definitions of variables}

Organisational culture: The sum total of the behaviours and practices, attitudes and beliefs, across the whole enterprise, for example, across an entire hospital ${ }^{22} 27$

Workplace culture: The more specific defining group characteristics within a component of an organisation, for example, intensive care unit, ward, department, section or professional grouping, for example, nursing or management ${ }^{9} 28$

Patient outcomes End results that consist of and can be used to measure the consequences of a patient's care, which can be positive or negative, and vary in severity. ${ }^{29}$ Refer to table 1 for examples. assess each study and classify them as 'high' or 'low' risk of bias. Any disagreements between the researchers will be resolved by discussion with a third and fourth researcher (KL, GL).

\section{Data synthesis}

Based on prior systematic reviews, it is not likely that the relevant articles will allow a quantitative meta-analysis of data. ${ }^{2}$ However, if this does eventuate, a random-effects model will be used. ${ }^{30}$ Heterogeneous data on patient outcomes will be analysed based on the nature of the variables, for example, a risk ratio for dichotomous outcomes, HR for time-to-event outcomes, rate ratio for counts or rates or standardised mean difference for continuous outcomes. A 95\% CI will also be calculated and applied..$^{30}$

\section{Confidence in cumulative evidence}

The strength of the studies will be assessed through the Grading of Recommendations Assessment, Development and Evaluation (GRADE) framework. To synthesise the research quality, we will assign each study on the GRADE rating scale for evidence quality (high, moderate, low, very low) and we will, as appropriate, provide Evidence Profile (EP) and Summary of Finding (SOF) Tables.

\section{CONCLUSION}

Organisational and workplace cultures are important concepts. Many policymakers, managers and clinicians conduct projects and initiatives aimed at influencing, shaping or altering their local cultures. We do not know the extent to which, and how, these strategies are related to downstream effects on patient outcomes. This review will inform future initiatives of this kind.

Acknowledgements The authors would like to thank Jeremy Cullis, Clinical Librarian, Macquarie University, for proving his expertise on the use of academic databases and for reviewing our search strategy.

Contributors JB led the study and provided a conceptualisation of the topic to the team. JH, KL, GL and LT developed the objectives and methods of the review including the search strategy. $\mathrm{JH}$ and $\mathrm{KL}$ produced the initial draft of the manuscript in conjunction with JB, with GL and LT providing critical revisions.

Funding This work is supported by NHMRC Program Grant 1054146.

Competing interests None declared.

Provenance and peer review Not commissioned; externally peer reviewed.

Open Access This is an Open Access article distributed in accordance with the Creative Commons Attribution Non Commercial (CC BY-NC 4.0) license, which permits others to distribute, remix, adapt, build upon this work noncommercially, and license their derivative works on different terms, provided the original work is properly cited and the use is non-commercial. See: http:// creativecommons.org/licenses/by-nc/4.0/

\section{REFERENCES}

1. Hesselink G, Vernooij-Dassen M, Pijnenborg L, et al. Organizational culture: an important context for addressing and improving hospital to community patient discharge. Med Care 2013;51:90-8.

2. MacDavitt $K$, Chou $S$, Stone $P$. Organizational climate and health care outcomes. Jt Comm J Qual Saf 2007;33(11 Suppl):45-56. 
3. Page A, ed. Keeping patients safe: transforming the work environment of nurses. Washington, DC: The National Academies Press, 2004.

4. Parmelli E, Flodgren G, Beyer F, et al. The effectiveness of strategies to change organisational culture to improve healthcare performance: a systematic review. Implement Sci 2011;6:1-8.

5. Scott T, Mannion R, Davies $\mathrm{H}$, et al. The quantitative measurement of organizational culture in health care: a review of the available instruments. Health Serv Res 2003;38:923-45.

6. Davies HT, Mannion R. Will prescriptions for cultural change improve the NHS? BMJ 2013;346:f1305.

7. Mannion R, Davies H, Marshall M. Cultures for performance in health care. Buckingham: Open University Press, 2005.

8. Braithwaite J, Westbrook MT, ledema R, et al. A tale of two hospitals: assessing cultural landscapes and compositions. Soc Sci Med 2005;60:1149-62.

9. Braithwaite J, Hyde P, Pope C. Culture and climate in health care organizations. Basingstoke, London: Palgrave Macmillan, 2010.

10. Braithwaite J. A lasting legacy from Tony Blair? NHS culture change. $J$ R Soc Med 2011;104:87-9.

11. Schein E. Organizational culture and leadership. San Francisco, CA Jossey-Bass, 2004.

12. Callen J, Braithwaite J, Westbrook Jl. The importance of medical and nursing sub-cultures in the implementation of clinical information systems. Method Inform Med 2009;48:196-202.

13. Callen JL, Braithwaite J, Westbrook Jl. Cultures in hospitals and their influence on and attitudes to, and satisfaction with, the use of clinical information systems. Soc Sci Med 2007;65: 635-9.

14. Martin J. Organizational culture: mapping the terrain. Thousand Oaks, CA: Sage, 2001

15. Gallego B, Westbrook MT, Dunn AG, et al. Investigating patient safety culture across a health system: multilevel modelling of differences associated with service types and staff demographics. Int J Qual Health Care 2012;24:311-20.

16. Davies $\mathrm{H}$, Nutley $\mathrm{S}$, Mannion R. Organisational culture and quality in health care. BMJ Qual Saf 2000;9:111-9.

17. Willis $\mathrm{CD}$, Saul J, Bevan $\mathrm{H}$, et al. Sustaining organizational culture change in health systems. J Health Organ Manag 2016;30:2-30.

18. Krueger L, Funk C, Green J, et al. Nurse-related variables associated with patient outcomes: a review of the literature 2006-2012. Teach Learn Nurs 2013;8:120-7.
19. Stalpers D, de Brouwer BJ, Kaljouw MJ, et al. Associations between characteristics of the nurse work environment and five nurse-sensitive patient outcomes in hospitals: a systematic review of literature. Int J Nurs Stud 2015;52:817-35.

20. Wong CA, Cummings GG, Ducharme $L$. The relationship between nursing leadership and patient outcomes: a systematic review update. J Nurs Manag 2013;21:709-24.

21. Sacks GD, Shannon EM, Dawes AJ, et al. Teamwork, communication and safety climate: a systematic review of interventions to improve surgical culture. BMJ Qual Saf 2015;24:458-67.

22. Wagner C, Mannion R, Hammer A, et al. The associations between organizational culture, organizational structure and quality management in European hospitals. Int J Qual Health Care 2014;26 (Suppl 1):74-80.

23. Scott $\mathrm{T}$, Mannion R, Marshall $\mathrm{M}$, et al. Does organisational culture influence health care performance? A review of the evidence. $J$ Health Serv Res Policy 2003;8:105-17.

24. Larson EL, Early E, Cloonan P, et al. An organisational climate intervention associated with increased handwashing and decreased nosocimal infections. Behav Med 2000;26:14-22.

25. Kinjerski V, Skrypnek BJ. The promise of spirit at work: increasing job satisfaction and organizational commitment and reducing turnover and absenteeism in long-term care. J Gerontol Nurs 2008;34:17-25.

26. Mannion R, Davies H. Culture in health care organizations. In: Ferlie E, Montgomery K, Pederson AR, eds. Oxford handbook of health care management. Oxford, UK: Oxford University Press, 2016:93-116.

27. Ashkanasy N, Wilderom C, Peterson M. Handbook of organizational culture and climate. Thousand Oaks, CA: Sage, 2000.

28. Jacobs R, Mannion R, Davies HT, et al. The relationship between organisational culture and performance in acute hospitals. Soc Sci Med 2013;76:115-25.

29. Nosrati H, Clay-Williams R, Cunningham F, et al. The role of organisational and cultural factors in the implementation of system-wide interventions in acute hospitals to improve patient outcomes: protocol for a systematic literature review. BMJ Open 2013;3:e002268.

30. Shamseer L, Moher D, Clarke M, et al. Preferred reporting items for systematic review and meta-analysis protocols (PRISMA-P) 2015: elaboration and explanation. BMJ 2015;349:g7647. 